\title{
Where do Chevrolet Volt Drivers in the EV Project Charge When They Have the Opportunity to Charge at Work?
}

March 2014

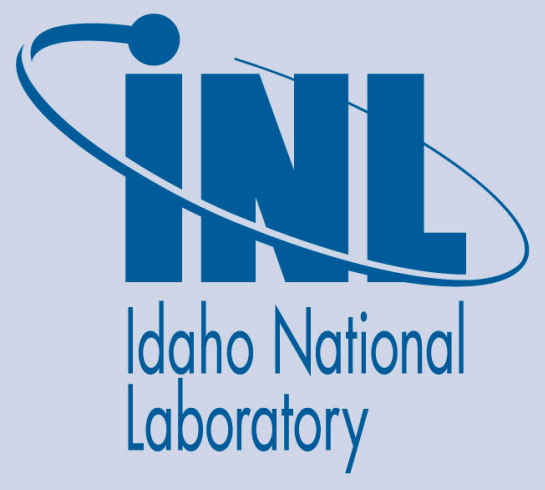

The INL is a U.S. Department of Energy National Laboratory operated by Battelle Energy Alliance 


\section{Where do Chevrolet Volt Drivers in the EV Project Charge When They Have the Opportunity to Charge at Work?}

March 2014

Idaho National Laboratory
Idaho Falls, Idaho 83415

http://www.inl.gov

Prepared for the

U.S. Department of Energy

Assistant Secretary for Energy Efficiency and Renewable Energy

Under DOE Idaho Operations Office

Contract DE-AC07-05ID14517 
Where do Chevrolet Volt drivers in The EV Project charge when they have the opportunity to charge at work?

March 2014

\section{Key Conclusions}

- A group of 96 Chevrolet Volts from The EV Project, whose drivers had the opportunity to charge at work, performed $57 \%$ of their charging events at home, $39 \%$ at work, and $4 \%$ at other locations over the period between January 1, 2013, and December 31, 2013. The proportion of charging energy consumed by location was similar.

- During this study period, this group charged their vehicles away from home more than 2.5 times as much as the overall group of Chevrolet Volt drivers enrolled in The EV Project.

- This study's drivers of Chevrolet Volts with workplace charging performed $92 \%$ of their away-from-home charging events at work and $8 \%$ at non-workplace away-from-home locations.

- On days when this study's drivers of Chevrolet Volts went to work, they performed $98 \%$ of their charging events either at home or work and only $2 \%$ at other locations.

- On days when this study's drivers of Chevrolet Volts did not go to work, they performed $89 \%$ of their charging events at home and $11 \%$ at other locations.

\section{Introduction}

There has been much discussion about where electric vehicle (EV) charging infrastructure should be installed. Some researchers have proposed that EVs will be charged primarily at locations where vehicles are naturally parked for the longest time. Travel surveys have shown that most vehicles are parked for the vast majority of time at home and at the work place [1]. Therefore, many researchers have assumed that most charging will be performed at home and work. This concept is commonly represented with a triangle similar to that shown in Figure 1. This figure represents the expectation that the majority of the charging will be performed at home, a significant amount of charging will be performed at work locations, and only a small amount of charging will be performed at other locations.

This paper investigates the actual charging location preferences of Chevrolet Volt drivers in The EV Project who had the opportunity to charge at work. Charging location preference is described in terms of the percentage of charging events performed and charging energy consumed at home, at the workplace, and at nonworkplace away-from-home locations.

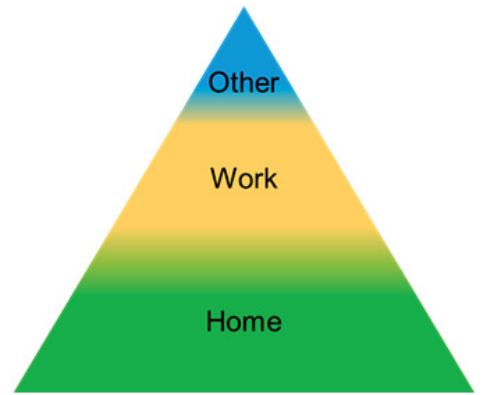

Figure 1: Common representation of expected EV charging frequency by location.

\section{Which Vehicles are Being Studied?}

Owners of Chevrolet Volts in 18 metropolitan areas across the United States participated in The EV Project. They agreed to allow project researchers to monitor the usage of their vehicles throughout the 3 -year project. From the overall group of participants, vehicles were selected that frequently parked at 97 work sites with known EV charging. These work sites are located in 15 metropolitan areas across the United States and vary in size from individual office buildings with small parking lots to large corporate complexes with multiple parking lots and garages. The type and amount of charging equipment also varies widely between sites, as well as the number and type of vehicles that could potentially charge at each site. Charging at some sites is open to the general public, while other sites restrict access to employees only. Some sites exact fees for charging and others offer free charging.

A group of 96 Chevrolet Volts enrolled in The EV Project was found to have frequently parked at these sites between January 1, 2013, and December 31, 2013. This set of privately owned vehicles performed over 29,000 charging events during the 1-year study period. This paper will describe the proportion of these charging events that occurred at home, work, and other locations. The 96 Chevrolet Volts in the sample hereafter will be referred to as "workplace vehicles."

As a requirement for participation in The EV Project, drivers of all workplace vehicles had the ability to charge at home. Each participant had an AC Level 2 (i.e., 240-volt) charging unit installed in their residence. They also had the opportunity to charge at work, based on the fact that they frequently parked at work sites where EV charging is available. It is important to note that workplace vehicles were included in the sample regardless of whether they 
were actually charged at work. This is a subtle but important distinction because some EV drivers may choose not to charge at work, even though they have the opportunity to do so.

\section{Discussion of Results}

Prior to analyzing workplace vehicles, the percentage of charging events performed, or charge frequency, and charge energy consumed by location was determined for all Chevrolet Volts in The EV Project during the 1-year study period. These results are shown in Figure 2, which shows $84 \%$ of charging events were performed at the vehicle's home location and $16 \%$ of charging events were performed away from home. Nearly the same proportion of energy was consumed at home and away from home.

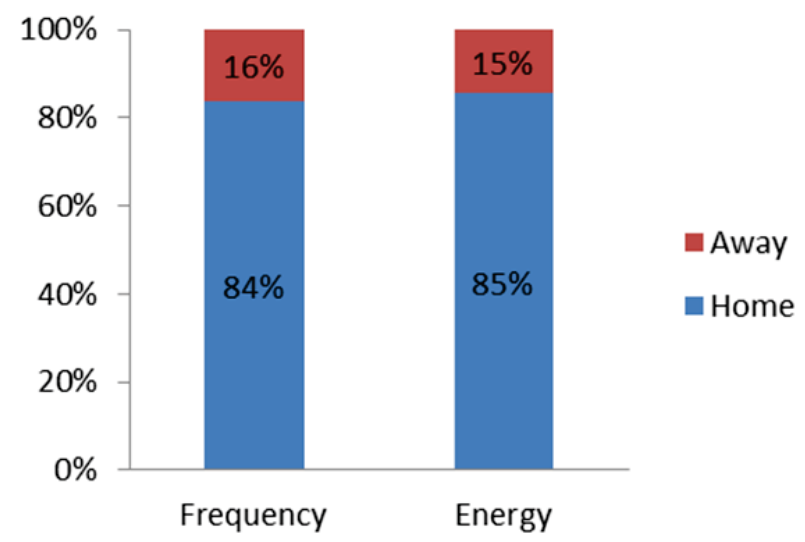

Figure 2: Charging frequency and energy consumption by location for all EV Project Chevrolet Volts in 2013.

The proportion of charge events performed and energy consumed by the workplace vehicles in the 1-year study period was then determined for home, work, and other away-from-home non-work locations (hereafter referred to as "other" locations). Figure 3 shows these results.

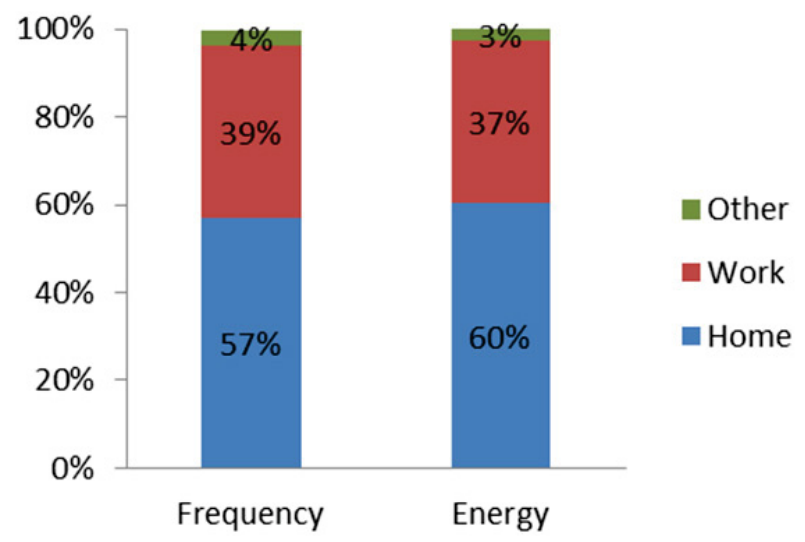

Figure 3: Charging frequency and energy consumption by location for workplace vehicles in 2013.
Similar to the overall set of vehicles, the relative proportions of charge frequency and energy consumption by location for the workplace vehicles was nearly equal, with only slightly more energy per charge at home than at work or other locations. The frequency and energy of home charging was considerably lower for workplace vehicles than for the overall group of EV Project Chevrolet Volts, indicating that workplace vehicles performed significantly more charging away from home.

Figure 3 also distinguishes the away-from-home charging between work and other locations. Comparing the sums of the work and other location charging frequency and energy in Figure 3 to the away-from-home charging in Figure 2 reveals that the workplace vehicles charged away from home more than 2.5 times as much as the overall group of EV Project Chevrolet Volts.

In addition, Figure 3 shows that workplace vehicle drivers performed only $4 \%$ of charge events and consumed $3 \%$ of charge energy at other locations. These locations could be any dedicated public or private charging station or 120-volt outlet outside of the work sites or the drivers' residences. Comparing charging at work to other locations, workplace vehicles performed $92 \%$ of their away-from-home charging at their work location and only $8 \%$ at other locations. This indicates that not only did the workplace vehicles conduct more away-from-home charging than the overall group of EV Project Chevrolet Volts, but the vast majority of that charging was at work.

Charge frequency of workplace vehicles by location is visualized in Figure 4 as a triangle, drawn to scale. This representation of actual results is similar to expected results often cited by researchers [2].

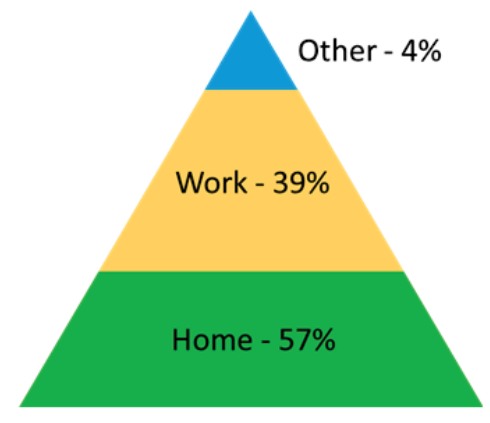

Figure 4: Charging frequency triangle for workplace vehicles drawn to scale.

Charging of workplace vehicles on the days they were parked at the work sites is displayed in Figure 5. On these days, charging at home and work accounted for $98 \%$ of charge events and $99 \%$ of charge energy. Very little charging occurred at other locations. This shows that, in aggregate, workplace vehicle drivers had little use for non- 
workplace public charging infrastructure on days they went to work.

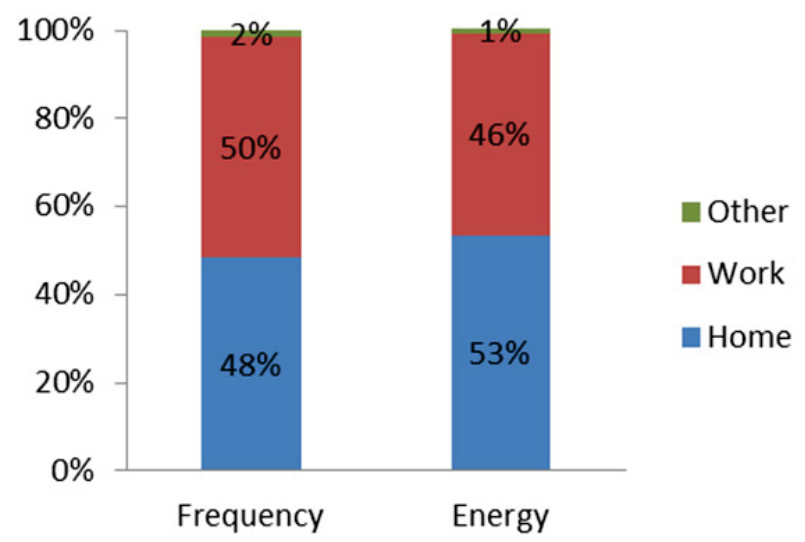

Figure 5: Charging frequency and energy consumption by location for workplace vehicles on days when they were parked at work sites.

Figure 6 shows charging of workplace vehicle on days when they were not parked at work sites. On these days, $11 \%$ of the charge events and $11 \%$ of the charge energy occurred at other locations. This is a significant increase over days when workplace vehicles went to work. However, non-work days represented only $30 \%$ of workplace vehicle calendar days in the study period.

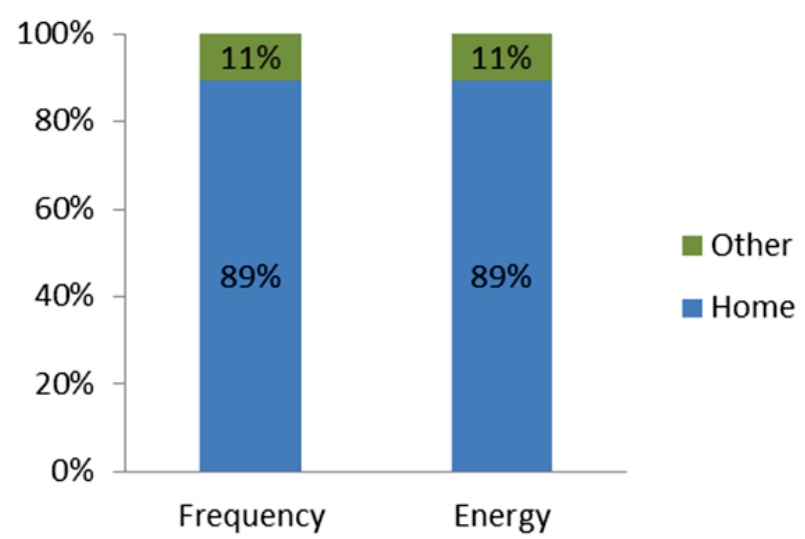

Figure 6: Charging frequency and energy consumption by location for workplace vehicles on days when they were not parked at work sites.

It is not yet clear how much the drivers of workplace vehicles depended on other charging locations to meet their desire for driving in electric-only mode. This question will be explored in future works to better understand the value of public charging infrastructure. Other factors need to be explored as well, such as the influence of commuting distance and the cost of charging on charging behavior.

\section{References}

[1] E. Tate and P. Savagian, "The $\mathrm{CO} 2$ Benefits of Electrification: E-REVs, PHEVs and Charging

Scenarios," SAE 2009-01-1311, April 2009.

[2] D. Bowermaster, "Plug-in Electric Vehicles Where Are We and What's Next?", Electric Power Research Institute, November 2013.

\section{About The EV Project}

The EV Project was the largest plug-in electric vehicle infrastructure demonstration project in the world, equally funded by the United States Department of Energy (DOE) through the American Recovery and Reinvestment Act and private sector partners. The EV Project deployed over 12,000 AC Level 2 charging stations for residential and commercial use, as well as over 100 dual-port DC fast chargers. Approximately 8,300 Nissan LEAF ${ }^{\mathrm{TM}}$, Chevrolet Volts, and Smart ForTwo Electric Drive vehicles were enrolled in the project.

Project participants gave written consent for EV Project researchers to collect and analyze data from their vehicles and/or charging units. Data collected from the vehicles and charging infrastructure represented almost 125 million miles of driving and 4 million charging events. The data collection phase of The EV Project ran from January 1 , 2011, through December 31, 2013. Idaho National Laboratory is responsible for analyzing the data and publishing summary reports, technical papers, and lessons learned on vehicle and charging unit use.

This material is based on work supported by DOE under Award Number DE-EE-0002194.

\section{Company Profile}

Idaho National Laboratory is one of DOE's 10 multi-program national laboratories. The laboratory performs work in each of DOE's strategic goal areas: energy, national security, science, and the environment. Idaho National Laboratory is the nation's leading center for nuclear energy research and development. Day-to-day management and operation of the laboratory is the responsibility of Battelle Energy Alliance.

For more information, visit avt.inl.gov/evproject.shtml. 